\title{
Practical solutions for LNG Fuelled Ships
}

\author{
Serena Lim, $\mathrm{PhD}$ \\ Ascenz Solutions \\ Singapore \\ serena.lim@ascenz.com \\ Zhiqiang $\mathrm{Hu}$, Prof \\ Newcastle University \\ United Kingdom \\ zhiqiang.hu@ncl.ac.uk
}

\section{Synopsis}

Liquified natural gas (LNG) as a fuel source for shipping is a ready-made solution for the maritime industry. LNG is a clean fuel that meets the current environmental regulations set by the International Maritime Organization (IMO) to lower the sulfur content of marine fuel from 3.5\% to $0.5 \%$ by January 2020 . LNG is also competitive in terms of price and the increasing availability of fueling terminals. This technological readiness promotes the adoption of LNG powered ships, and the demand for such ships is increasing and is projected to increase in the future. LNG fuelled ships (LFS) comply with the tightened emission regulations, and major industry players have predicted that more than $10 \%$ of the world fleet will be using gas as a fuel by 2035 . The rapid increase in the design and use of LFS has to be carefully monitored to ensure a successful transition.

The design of ship and containment systems for LFS is usually carried out using risk-based design processes. Monitoring and advisory solutions are critical to ensure that changes take place in a safe manner. The experience and lessons learned from designing a suitable database framework and data analytics for traditional ship design are presented, and the knowledge transfer and applications for LFS are discussed. Additional critical parameters that are specific to LFS are discussed, and procedures required to ensure quality data collection to provide necessary solutions for the future fleet are presented. The importance of monitoring quality and quantity of the bunkering process with traditional fuel is outlined along with strategies to adopt and promote infrastructure readiness for the increase in LFS use. Data management and big data analysis for decision making is becoming increasingly apparent in many industries, including the shipping industry. Therefore, the inclusion of the systematic design of data acquisition and analytics systems for newly designed LFS is needed. This will accelerate data-driven knowledge generation and design improvements, promote safe and efficient ship operations, and provide a solid foundation for automation. The synergistic blending of solutions from fuel suppliers, engine makers, containment providers, sensor makers, logistics and government will be needed to ensure the global growth and sustainability of LNG fuelled shipping.

Keywords - LNG Fuelled Ships (LFS), Smart shipping, Digitalisation, Clean energy, Robust database, Data standardisation

\section{Introduction}

Ocean freight remains one of the most efficient ways to move cargo across the world. The shipping industry contributes to $3 \%$ of the global $\mathrm{CO}_{2}$ emissions and $10 \%$ of transport emissions (Smith, 2015). One of the efforts to tackle the sulphur emission problem such as retrofitting and installation of scrubbers has become popular as a way to address sulphur emissions, with more than 3000 vessels, where about 857 are from new building projects (Ship\&Bunker, 2019). However, such a solution is viable but with complications (Vallero, 2014).

Another possible manner of tackling the emission is by choosing an alternative fuel such as the use of LNG. This approach shows promising environmental performance and can achieve low carbon ship transports targets (Bengtsson et al, 2012). LNG has nearly no sulphur content and produces very low NOx emissions compared to 
typically burned marine fuel such as the heavy fuel oil and marine diesel oil. The new regulations of the IMO 2020 sulphur fuel cap of $0.5 \%$ mass by mass (IMO, 2016) has also boosted the number ships adopting LNG as a fuel for ships.

LNG as a fuel for the shipping industry is not new. The vast application to date is on LNG carriers. Liquefied natural gas is increasingly adopted as marine fuel also for ships other than LNG carriers. In 2017, the adoption of LNG fuelled ships reached 132 vessels, with 140 more under construction (GTT, 2019). Figure 1 shows the yearly development of LFS showing an increase of ships on order. The most significant operating area of LFS is Norway with 61 ships, and the majority of ships on order will be operating in Europe, with 57 ships (DNV GL, 2018).

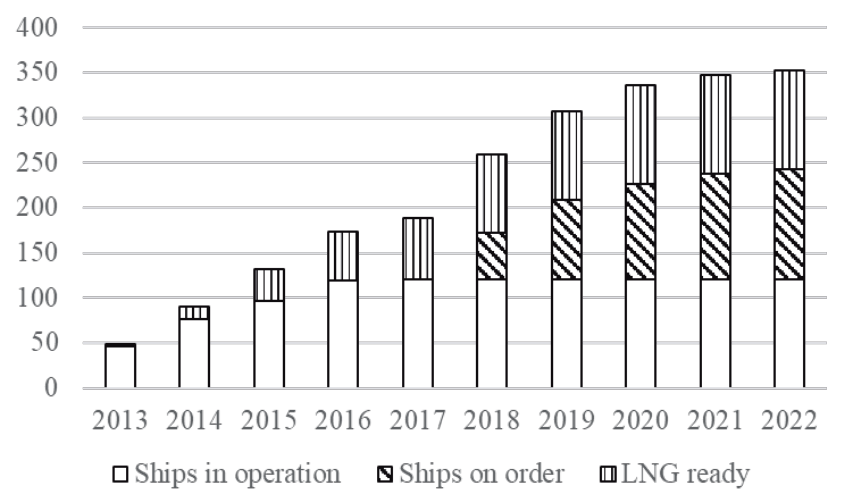

Figure 1: Yearly development of LNG fuelled ships (DNV GL, 2018)

LNG uptake by vessel segment is shown in Figure 2. Among the ships on order, 34 of them are tankers, 21 container ships, 17 cruise ships, 14 passenger ferry and specialised vessels respectively. Other types of vessel that will embark using LNG as a fuel are such as RoPaxs, tugs, PSVs, bulk carriers, car carriers, HSLC and Ro-Ro. These vessels will be supported by the increasing number of infrastructure such as the number of LNG ports, whereby a total of 139 ports will be in operation worldwide by 2020 (Sea LNG, 2017).

The solution of LNG as a fuel, besides being economically viable, the claims of effectiveness of different solutions adopted to tackle emissions has to be evidence-based, and this requires a systematic approach of continuous assessment and refinement (Wan, 2018). A feasible way to address this is through real-time data monitoring of vessels, since accurate data contributes to evidence-based policymaking (Sanderson, 2002). A continuous data monitoring system will allow the collection of evidence during vessel operations.

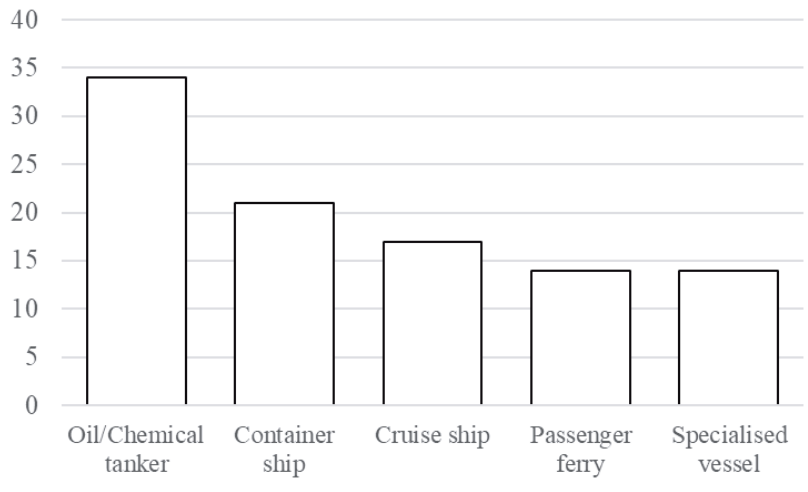

Figure 2: LNG uptake by vessel segment (DNV GL, 2018)

The shipping industry has been encouraging the use of the Ship Energy Efficiency Management Plan (SEEMP), which recommends a four step process of Planning, Implementation, Monitoring and Analysis (IMO, 2016). Automation of data monitoring is well received by the industry, especially in recent years of monitoring and advisory systems on vessels such as containers, tankers, bulk carriers and cruise ships.

Energy efficient ship research relies on real data acquired during ship operation. The low frequency data collection approach uses data from noon reports, whilst higher frequency data collection relies on sensors installed onboard vessels which transmit data to a recorded platform.

The single platform data collection on ships that have been tested to measure the performance of vessels is adopted. The lessons learned from such a platform in terms of the overarching methodology to survey vessel, approach for sensor installation, data validation, data unification are summarised in this paper. The data collection and data processing platform will be readily integrated on LFS. The additional parameters specific to LNG applications have to be added to deliver a holistic approach for vessel performance monitoring. In addition to providing advisory guidance for optimum vessel performance, the data platform also offers another layer of safety monitoring using sensor data.

The most important standout considerations of an LFS compared to a typical ocean going vessel is 
the containment system of the fuel. The natural properties of LNG have to be taken into account, such as the issue of boil off gas, temperature control and changes of fuel composition with time (Dobrata, 2013; Ding, 2008; Miana, 2010). There are different types of containment system for LNG used in LFS. The membrane type containment system that is commonly used for LNG carriers will be further discussed for LFS applications.

This paper will also discuss in detailed the considerations needed when capturing data from LFS, which usually includes many parameters considered for typical seagoing vessels as well as LFS specific data. The practical solutions can be derived from such data, for example, the monitoring of boil off gas and LNG ageing. Measurement of the safety of LNG containment systems using data will also be discussed.

\section{LNG Fuelled Ships}

The ability to operate LFS is due to the development of engines that are capable of burning LNG and the technology to contain LNG safely in the harsh ocean environment. For the LNG to be used for propulsion of a vessel, it needs to go through a vaporiser, gas heater and gas valve units (two-phase safety). Most of the engines are dual-fuel engines that burn both LNG and feeds from a fuel oil tank (AEsoy, 2011). An important difference to consider when comparing LFS to LNG carriers is the LNG fuel containment system.
Through a detailed understanding of LNG properties and the importance of solutions that are needed for LFS, the identification of parameters and associated sensors are identifiedfor effective data acquisition. These data will be able to generate information to practical solutions and advisory during operations, and in the long run, lessons learned could feedback into new designs.

Figure 3 shows a systematic methodology to develop a data acquisition system for LFS that allows data to provide suitable insights for practical solutions for LFS. First is to understand the problem statement, second is to identify the data needed and third, to create value from collected to generate practical solutions for LFS.

The approach is divided into two parts for a clear understanding of the requirements. The first problem breakdown is to identify LNG specific problems such as the fuel and containment system and also the engine properties that need to be aware off when burning LNG as a fuel. The second problem breakdown is to view the LFS from the perspective of a typical ship, such as to identify potential engine efficiencies and approaches to optimise ship operations. Once the problem statement is clear, the solutions needed will become evident. Hence, sensors can be identified for parameters that are required to be recorded to provide data for specific solutions. Data are then logged on a single platform to enable quick and effective processing.

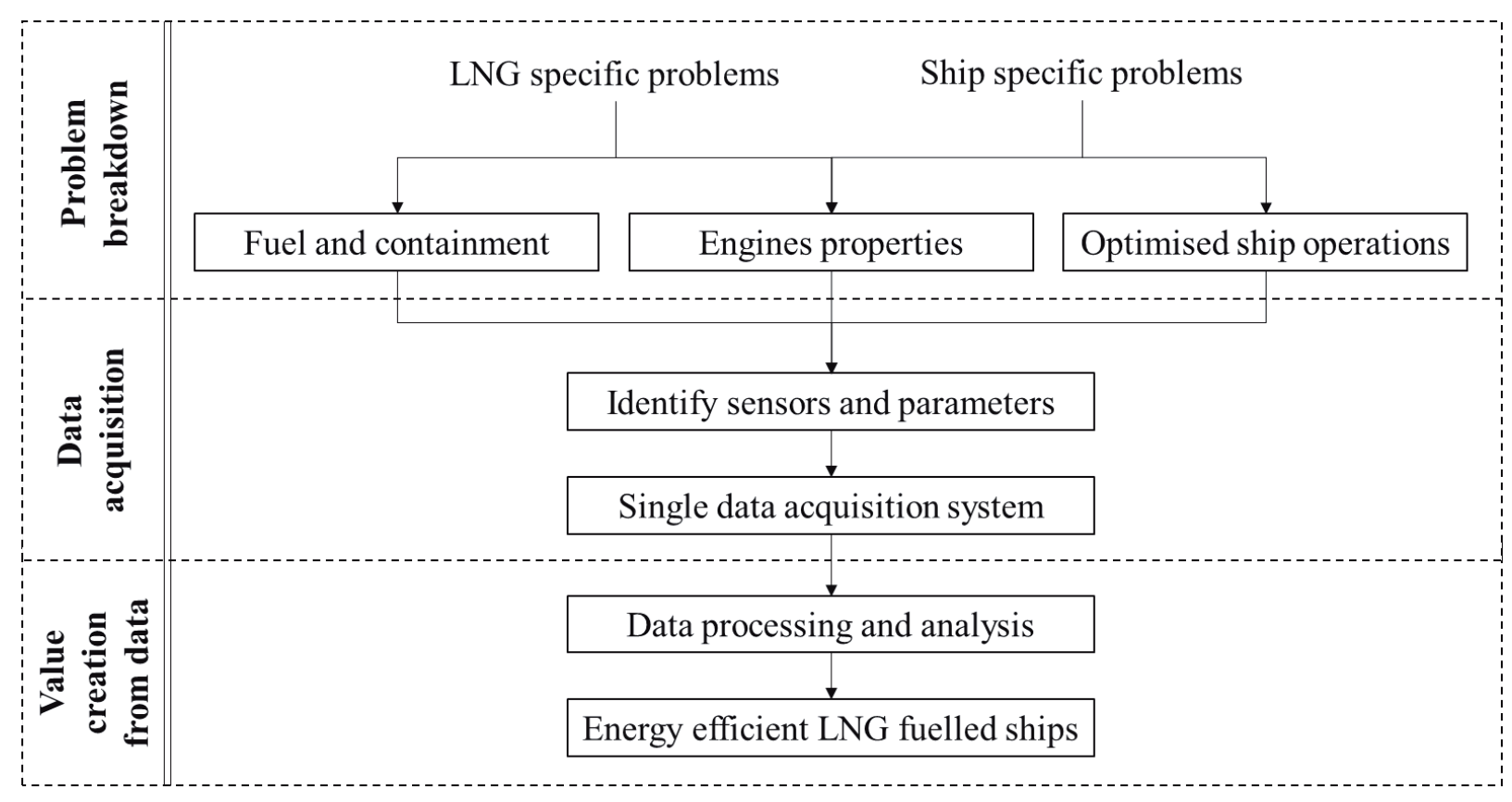

Figure 3: Methodology to develop data acquisition system for LFS 


\subsection{LNG Specific Solutions}

To be able to understand what types of parameters and information are essential when collecting data from LFS, the topics that are particularly relating to LNG are studied, such as the composition of LNG, methane number, boil off gas, LNG ageing, roll over and knocking, as illustrated in Figure 4. These phenomenon causes losses of cargo, affecting both the environment and safety. The implication of these also depends on the engine type, if the fuel is premixed or using injection; and whether the engine uses spark plug with prechamber gas or diesel pilot and accommodates for dual fuel. These properties that are important to LNG can be monitored for safety and optimised to improve performance.

\subsubsection{Composition of LNG}

LNG is made up of different composition such as methane, nitrogen, ethane, propane and butane. Methane is the main content of LNG, and the LNG composition is important to determine the overall quality. The composition of LNG varies and is dependent on the source and method of liquidation.

\subsubsection{Methane number}

Methane number $(\mathrm{MN})$ is a quality measurement for LNG, which indicates fuel capability to avoid knocking in the engine. LNG with higher MN has a higher content of methane (CH4), which provides a better quality of gas (Tjojudo et al, 2018). The $\mathrm{MN}$ is particularly crucial for engines with premixed combustion. The $\mathrm{MN}$ has direct effect on the power density and thermal efficiency. The MN also plays a vital role in the knock resistance of $\mathrm{LNG}$.

\subsubsection{Boil off-gas}

LNG is kept in containment tank below the boiling point of $160^{\circ} \mathrm{C}$. The external heat that comes through the walls of the containment system, pushing the LNG beyond the boiling point and causing it to evaporate. Nitrogen and methane which have lower boiling point will evaporate first compared to other composition. Natural boil off happens throughout the voyage; however, in order to have enough LNG to support the propulsion and auxiliary, forced boil-off gas is needed.

\subsubsection{LNG ageing}

LNG ages by time, hence, long term storage of LNG requires careful monitoring of changes in quality and properties of the fuel. This is caused by the evaporation of the volatile components in the LNG, leaving behind higher heavier components (Ernebrant et al, 2017). The changes in the composition of the LNG through time is the ageing of the fuel.

\subsubsection{Roll-over}

LNG rollover happens when new LNG is added into a tank with LNG remaining in it. The two batches of LNG will have different compositions temperatures and densities. Such mixing causes increase of boil off rates, and pressure increase in tanks (Kulitsa, 2018). The rise of pressure in the tank is controlled by a safety venting devise that vents the flammable boiled off gas into the atmosphere. The venting relieve valve must be able to cope when there is a sudden rapid increase of boil off gas, causing a sudden increase of overall pressure in the tank. The internal pressure of the tank has to be monitored as not to cause damage to the containment system. Proper control of the roll-over will be able to reduce the amount of boil off gas.

\subsubsection{Knocking}

Knocking happens when the fuel pre-ignites due to compression from fuel-air mixture rather than from the spark plug. The knocking is usually violent and spontaneous. Engine knocking not only reduces engine performance, but it also damages the engine and increases pollutant. The engine control system has to be monitored to minimise knocking when burning a wide range of fuel. The knocking is particularly crucial for LNG engines with premixed combustion.

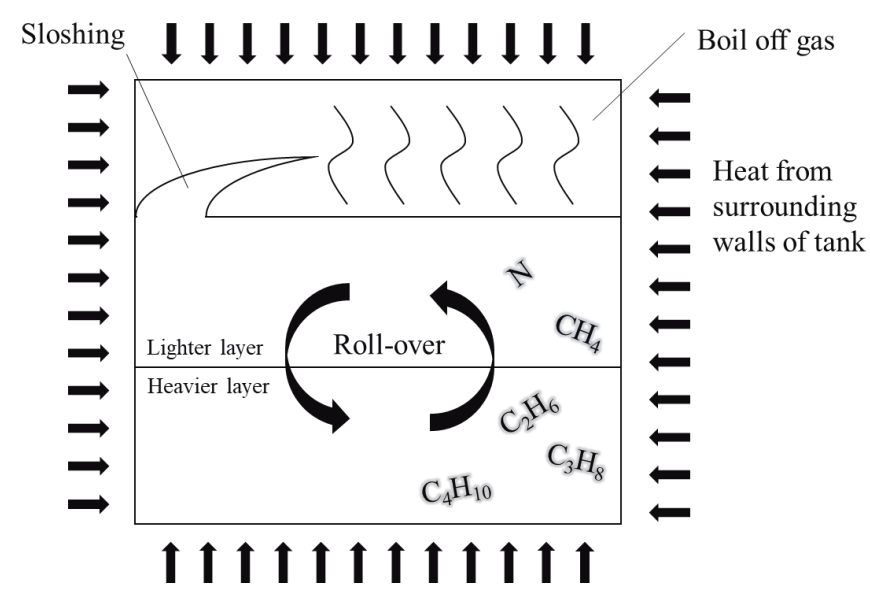

Figure 4: LNG uptake by vessel segment (DNV GL, 2018) 


\subsection{Ship Specific Solutions}

Different solutions have been adopted to improve energy efficiency on ships during operations using knowledge informed by data. Among the decision making solutions proposed by data are voyage and route optimisation, trim optimisation, speed optimisation, ensuring hull efficiency through hull cleaning and energy flow management.

\subsubsection{Ship resistance}

Most of the optimisation is based on the principle of reduced resistance of the ship during operation. The overall ship resistance can be further subcategories from the contribution of air resistance, wave making resistance and viscous resistance. These resistance are much affected by the ships speed, as illustrated in Figure 5. The air resistance depends on the projected area of ship above waterline, wind velocity and direction. Fully loaded container vessel will have more air resistance as compared to a bulk carrier. The wave waking resistance is affected hugely by the shape of the hull form and the speed of the vessel. The viscous resistance also increases with the ships speed and is affected by the immersed surface area of the ship in water.

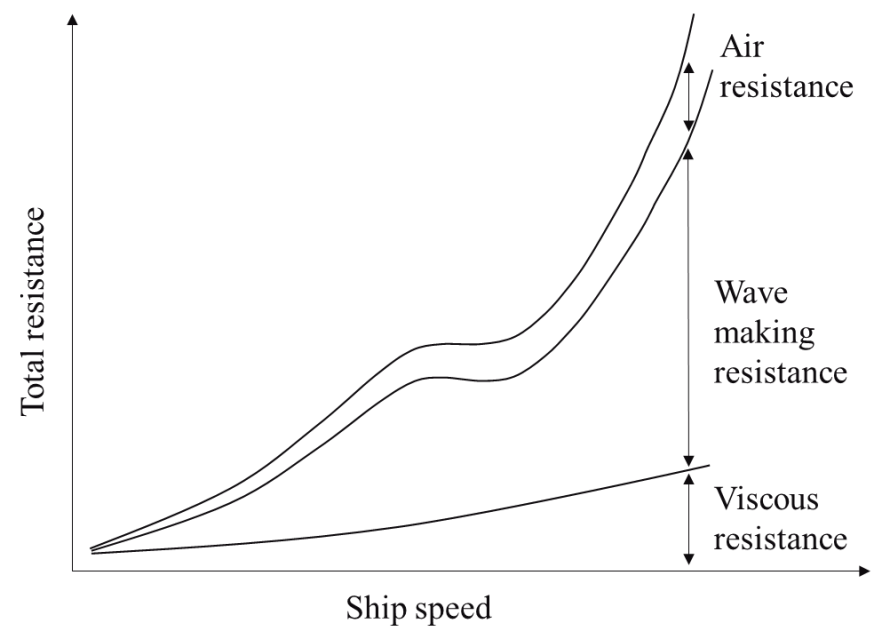

Figure 5: Components of resistance that makes up total resistance for a moving ship

Quantifying the total resistance can help to predict the power needed to move the body through water at the required speed. The higher the speed of the vessel, the more fuel is needed to provide power. Through proper understanding of total resistance and power, the optimum speed and trim for a particular ship can be proposed.

\subsubsection{Energy management}

The overall energy demand to carry out ship operation is understood so that holistic energy management of the ship can be identified and the number of engines at specific loads can be adapted to meet the operational needs. Engine efficiency can be measured using specific fuel oil consumption, which is derived from fuel consumption to produce the needed power. This can be optimised by operating the engine at the best percentage maximum continuous rating (\%MCR). For ships that have more than one main engine or auxiliary engine, the number of engine in operation at the best load can be determined if known power requirements. By operating the optimum number of engines at the optimum rate leads to proper management of energy efficiency.

Most of the LFS designs are suited for the dualfuel propulsion system and cryogenic gas handling technology. The whole vessel energy management can be achieved through clear operational breakdown and identifying the amount of energy needed during each operation. Much work has been successfully carried out to provide optimised ship specific solutions informed by data (Lim, 2016; Baldi, 2018).

\section{LNG Containment Systems}

The LNG containment systems are also discussed as different containment has its own challenges. The LNG specific solutions are more relevant, depending on the type of containment system selected. LFS consist of containment system that stores LNG. The independent tank types can be classed as IMO type-A, type-B and type-C. Another type of tank is the membrane-type tank that is embedded in ship structure. Each of the containment systems presents its own advantages. The understanding of the containment system is essential to understand which parameters are important to be logged. The data collected will be used to provide different practical solutions that are useful during vessel operations. Table 1 provides a general comparison between different LNG containment systems (images from liquifiedgascarrier.com). All of the tanks can withstand cryogenic conditions of LNG.

The world's first LNG fuelled container ship, the Isla Bella, uses the c-type containment system. Ctype tanks are pressurised. The advantages of Type-B containment system provides operational flexibility that is sloshing free and has no filling 
Table 1: Types of LNG containment system

\begin{tabular}{|c|c|c|c|c|}
\hline & Type-A & Type-B & Type-C & Membrane type \\
\hline $\begin{array}{l}\text { Hull } \\
\text { integration }\end{array}$ & Independent & Independent & Independent & Integrated \\
\hline $\begin{array}{l}\text { Containment } \\
\text { shape }\end{array}$ & Prismatic & Prismatic, spherical & Cylindrical, bilobed & Prismatic shape \\
\hline $\begin{array}{l}\text { Design } \\
\text { vapour } \\
\text { pressure }\end{array}$ & $<0.07 \mathrm{MPa}$ & $<0.07 \mathrm{MPa}$ & $\begin{array}{l}>2000 \text { mbar } \\
\text { High pressure }\end{array}$ & $<0.025 \mathrm{MPa}$ \\
\hline $\begin{array}{l}\text { Secondary } \\
\text { barrier }\end{array}$ & Full & Partial & None & Full \\
\hline Sloshing & Yes & Yes (low) & No & Yes \\
\hline $\begin{array}{l}\text { Containment } \\
\text { volume/space }\end{array}$ & High & Low & Low & High \\
\hline $\begin{array}{l}\text { Pressurised } \\
\text { tank }\end{array}$ & Low & Low & High & Low \\
\hline Boil off gas & High & High & Low & High \\
\hline
\end{tabular}

limit.. It also provides volume efficiency with the prismatic shape and hull optimised tank. Both type A and B are structural tanks built into the hull that are not highly pressurised. Such containment system requires constant consumption of boil off gas (BOG). The Type-C is cylindrical LNG fuelled tanks. The advantages of such containment system is that is modular and can be readily installed on vessels. Due to the high pressure tank, the BOG problem is reduced. The downside of such a vessel is the size of the containment system that requires more space to volume of containment. This leads to potential losses of fuel spaces, especially container vessels.

The membrane type containment system advances with thermal and mechanical performance. Layers of the membrane are designed to maximise space

On-board data acquisition system

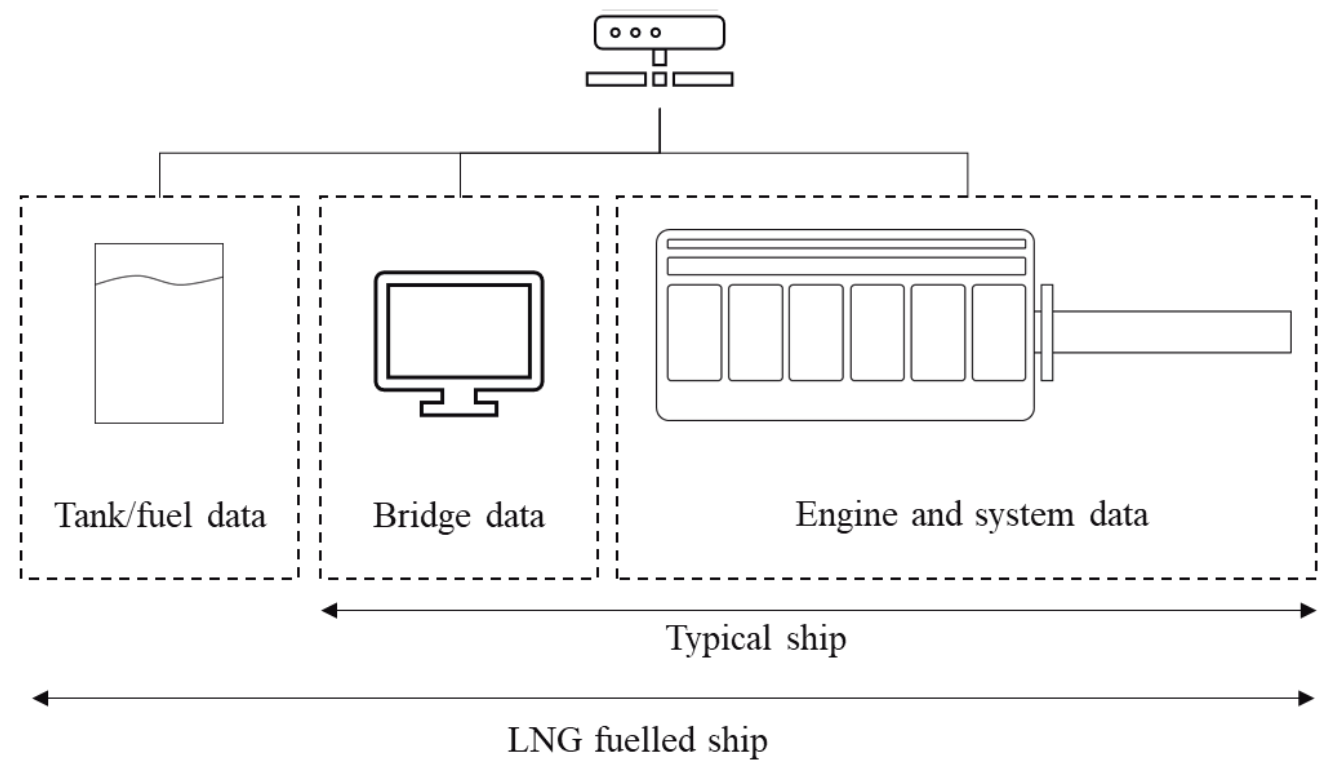

Figure 6: On-board data acquisition system 
utilisation and reduce boil off gas from $0.7 \%$ to $0.07 \%$ of volume per day. The challenge of partial tank filling was overcome to adapt for LFS usage, and the reinforced membrane enable such technology to withstand the sloshing load that is high in prismatic tanks. Insulation reinforcement and higher density materials were used to increase practicality of usage for LFS

Thought a good understanding of LNG specific and ship specific requirements, the data acquisition for LFS can be mapped out.

\section{Data Acquisition}

Through proper understanding of LNG specific and ship specific requirements, the data acquisition for LFS can be mapped out. Figure 6 illustrates a comparison between the on-board data acquisition system of a typical ship and the addition consideration needed for an LFS.

Real time data are logged on a common platform that allows a more holistic approach for data management and data processing. The data can be time stamped in a single database, and the entire activity of the vessel can be reconstructed and understood. The processed data are typically displayed on the bridge and engine control room, and visible for the crew to understand specific activity of vessel through data visualisation. Data is also sent back to shore to allow further management and allows fleet comparison.

\subsection{Sensors and Parameters}

A systematic approach to ensure that all essential parameters are logged on a single platform is to provide a good understanding of entire vessel operation. This approach can be divided into three main components, the data that can be gathered on the bridge, the data from the engines and system data, and the data for fuel management. Tables 2, 3 and 4 show the parameters from each data section and examples of sensors to acquire such data.

Table 2: Examples of bridge data

\begin{tabular}{|c|c|}
\hline \multicolumn{2}{|c|}{ Bridge data } \\
\hline Parameter & Sensor example \\
\cline { 1 - 1 } Speed overground & \multirow{2}{*}{ GPS } \\
\cline { 1 - 1 } Latitude, Longitude & \\
\cline { 1 - 2 } Vessel draft & Draft sensor \\
\hline Rudder angle & Potentiometer \\
\hline Speed through water & Doppler sensor \\
\hline Rudder angle & Potentiometer \\
\hline
\end{tabular}

\begin{tabular}{|c|c|}
\hline $\begin{array}{c}\text { Wind intensity and } \\
\text { direction }\end{array}$ & Anemometer \\
\hline Water depth & Echosounder \\
\hline Vessel heading & Gyrocompass \\
\hline
\end{tabular}

Most of the bridge data can be obtained through NMEA 0183, a communication protocol for electronics by National Marine Electronics Association (NMEA). Other environmental data can also be obtained from the bridge, such as atmospheric pressure, atmospheric temperature, sea water temperature and salinity.

Table 3: Examples of engine and system data

\begin{tabular}{|c|c|}
\hline \multicolumn{2}{|c|}{ Engine and system data } \\
\hline Parameter & Sensor example \\
\hline Fuel flow rate & Coriolis meter \\
\hline Cylinder pressure & Pressure sensor \\
\hline $\begin{array}{c}\text { Electrical current and } \\
\text { voltage }\end{array}$ & Current inductor \\
\hline Shaft speed & Tachometer \\
\hline Shaft torque, thrust & Strain gauge \\
\hline $\begin{array}{c}\text { Energy consumed by } \\
\text { each consumer and } \\
\text { energy load balance }\end{array}$ & Control unit \\
\hline
\end{tabular}

The fuel flow rate is measured at different points, and the inflows are measured from both the natural boil off gas and the forced boil off gas. The fuel consumed is measured from the inlet and outlet fuel pipe of the engine. These parameters allow good understanding of total energy consumed by the engines. The aggregated values of the main and auxiliary engines, being the most significant consumers on-board are used for better understanding of main converters on-board the vessel. The power output of the engine is also measured to understand the efficiency of the engine and the overall energy needed by the vessel

The hydrodynamics of an LFS are very similar to typical non LNG powered vessels. In order to improve the efficiency of vessel, the basic principles to reduce ship resistance is assumed. Core parameters to monitor ship condition during operation are observed; the typical parameters are monitored to access ship efficiency. 
Table 4: Examples of tank and fuel data

\begin{tabular}{|c|c|}
\hline \multicolumn{2}{|c|}{ Tank/fuel data } \\
\hline Parameter & Sensor example \\
\hline LNG composition & Gas chromatography \\
\hline Vapour pressure & Pressure gauge \\
\hline Vapour temperature & Thermometer \\
\hline Liquid temperature & Thermometer \\
\hline Liquid density & Densitometer \\
\hline $\begin{array}{c}\text { Temperature within } \\
\text { tank insulation }\end{array}$ & Thermometer \\
\hline
\end{tabular}

The tank and fuel data collected are also used to The tank and fuel data collected are also used to support smooth operations. During loading and offloading of fuel, the tank has to be within a good range of temperature; hence mists of $\mathrm{LNG}$ are sprayed in the tank to control tank temperature. Such forced cooling will reduce the waiting time at port for the tank temperature to arrive at suitable temperature. This will also reduce boil off rates and slow down LNG ageing to enable better management of fuel. Further measurements of density of the liquid at each tank level are also necessary to model LNG ageing during vessel operation. These parameters are also used to prevent roll-over.

\subsection{Practical Data Usage}

The data acquired from different systems on-board the vessel are used to monitor safety and to optimise overall vessel performance. Most of the parameters can be obtained using sensors, as stated in section 4.1 or alternative sensors. Sensor selection will depend on the sensitivity needed, available budget and also physical space available for installation. For example, the vessel trim can be derived from Inertial Measurement Unit (IMU) which encompasses from accelerometers, gyroscopes, and magnetometers. Such sensors are also useful to understand vessel motion and the interaction motion of LNG in the tank.

The quality of the data from sensors are essential and have to be monitored closely. Specific data check and cross data validation have to be coded into data acquisition system to notify when sensors are behaving outside the usual boundary conditions. The calibration procedures have to be followed periodically. Under certain conditions when the data is showing abnormal behaviour, crew on-board and personnel observing the data will have to troubleshoot and investigate if the data is not reflecting the actual condition of the vessel operation.

With the increasing number of LFS to come, most crew will be operating such vessels and will take time to learn the details and overarching ship performance using LNG. The visualisation of data from the on-board data acquisition system will be able to provide quick insights into the operation to create awareness and also to facilitate understanding of the overall operation, especially when handling LNG.

Despite continuous improvements carried out on LNG membrane, there is still a fraction of heat input from the surrounding, causing LNG to boil off. By obtaining data from the tank and understanding operational needs, an optimised way to manage and utilised LNG boil off can be refined.

The parameters logged during vessel operations can also be used for data-driven analysis and tested using machine learning approaches. Learning from data will enable modelling to predict potential failure before it happens.

Advisory systems and improvements of control systems can be built upon the data. When proposing advisory systems, the boundary conditions during operation of the vessel have to be clarified and taken into account during modelling. This will enable practical implementation of the system during operations.

\section{Conclusions}

The number of LFS will continue to increase, structured data collected from the commissioning of the vessel will enable technical challenges to be resolved and solutions to be streamlined. The top view and considerations needed to provide practical solutions for LFS based on data are discussed. From both the solutions needed to overcome complexity of using LNG as a fuel with the embedded thought of operating ships efficiently. The knowledge generated from these data will be able to advise design of LFS and provide exponential learning to the industry.

\section{Acknowledgements}

The authors sincerely thank Francois Hanat, Marc Bonnissel and the team from GTT for insights and advice regarding effective containment systems for LNG and the practical solutions discussed. 


\section{References}

AEsoy, V., Einang, P.M., Stenersen, D., Hennie, E. and Valberg, I., 2011. LNG-fuelled engines and fuel systems for medium-speed engines in maritime applications. SAE Technical Paper No. 2011-01-1998.

Baldi, F., Ahlgren, F., Nguyen, T.V., Thern, M. and Andersson, K., 2018. Energy and exergy analysis of a cruise ship. Energies, 11(10), p.2508.

Bengtsson, S., Fridell, E. and Andersson, K., 2012. Environmental assessment of two pathways towards the use of biofuels in shipping. Energy Policy, 44, pp.451-463.

Ding, S.F., Tang, W.Y. and Zhang, S.K., 2008. A Research on temperature field and stress field of large-scale LNG ship. Ship Engineering, 5.

DNV GL, 2018. LNG regulatory update. "Best fuel of the future". Available at: http://www.golng.eu/files/Main/20180417/2.\%20.

Dobrota, Đ., Lalić, B. and Komar, I., 2013. Problem of boil-off in LNG supply chain. Transactions on maritime science, 2(02), pp.91100.

Ernebrant, S., Johansson, T., 2017. Studies regarding the ageing of fuel. LNG blue corridors. Seventh framework programme. LNG BC D3.11.

GTT, 2019. LNG-fuelled shipping goes large scale. Available at: https://www.gtt.fr/sites/gtt/files/lng_industry__gtt_march2019.pdf.

IMO, 2016. Guidelines for the development of a ship energy efficiency management plan (SEEMP), MEPC.282(70). Available at: https://www.classnk.or.jp/hp/pdf/activities/statuto ry/seemp/seemp-mepc282-70.pdf.

IMO, 2016. Marine Environment Protection Committee (MEPC), 70th session, 24-28 October 2016. Available at : http://www.imo.org/en/MediaCentre/MeetingSum maries/MEPC/Pages/MEPC-70th-session.aspx.

Kulitsa, M. and Wood, D.A., 2018. LNG rollover challenges and their mitigation on Floating Storage and Regasification Units: New perspectives in assessing rollover consequences.
Journal of Loss Prevention in the Process Industries, 54, pp.352-372.

Lim, S., Pazouki, K., Murphy, A.J., Younessi, S. and Graham, N., 2016. Systematic rationale for assessing energy flow across the entire vessel operation. Energy Efficient Ships 2016. London, UK.

Lim, S., Turkman, S., Rostami, A.B., Prini, F., Kurniawati, V., Carchen, A., Gibson, M., Benson, S.D., Pazouki, K., Murphy, A.J. and Dow, R.S., 2018. Ship performance-using the real world as a laboratory. In Full Scale Ship Performance Conference. Newcastle University.

Miana, M., Del Hoyo, R., Rodrigálvarez, V., Valdés, J.R. and Llorens, R., 2010. Calculation models for prediction of Liquefied Natural Gas (LNG) ageing during ship transportation. Applied Energy, 87(5), pp.1687-1700.

Sanderson, I., 2002. Evaluation, policy learning and evidence-based policy making. Public administration, 80(1), pp.1-22.

Schinas, O. and Butler, M., 2016. Feasibility and commercial considerations of LNG-fueled ships. Ocean Engineering, 122, pp.84-96.

Sea LNG, 2017. Bunkering infrastructure, more LNG bunkering facilities are being built. Available at: https://sea-lng.org/lng-as-a-marinefuel/bunkering-infrastructure/.

Ship\&Bunker, 2019. Number of vessels opting for scrubbers quadruples in 12 months. Available at: https://shipandbunker.com/news/world/950057number-of-vessels-opting-for-scrubbersquadruples-in-12-months.

Smith, T. W. P., Jalkanen, J. P., Anderson, B. A., Corbett, J. J., Faber, J., Hanayama, and Pandey, A. (2015). Third IMO Greenhouse Gas Study 2014. Available at: http://www.imo.org/en/OurWork/Environment/Po llutionPrevention/AirPollution/Documents.

Tjojudo, D.H. and Kartohardjono, S., 2018. Methane Number Improvement of Gas from LNG Regasification Unit. E3S Web of Conferences Vol. 67, p. 04033. 
Vallero, D., 2014. Fundamentals of air pollution, $5^{\text {th }}$ edition. Academic press, pp 829-879.

Wan, Z., El Makhloufi, A., Chen, Y. and Tang, J., 2018. Decarbonizing the international shipping industry: Solutions and policy recommendations. Marine pollution bulletin, 126, pp.428-435.
Wang, S. and Notteboom, T., 2014. The adoption of liquefied natural gas as a ship fuel: A systematic review of perspectives and challenges. Transport Reviews, 34(6), pp.749-774. 